\title{
Experimental investigation of moving particles in rotating drum
}

\author{
Karolina Skoczkowska ${ }^{1, \mathrm{a}}$, Roman Ulbrich ${ }^{1}$ \\ ${ }^{1}$ Opole University of Technology, Opole 45-271, Mikołajczyka 5, Poland
}

\begin{abstract}
This paper is about cataracting motion in a rotating drum. The research was carried out for three types of filling. A PIV program - which allows to determine the local velocity field and particles trajectory - was applied to define the filling behaviour. Experimental and calculated (by the Oyama equation) results have been compared. An attempt to revision of implemented model notation have been undertaken, so that a better description of start- and final-cataracting motion will be achieved.
\end{abstract}

\section{Introduction}

Rotational drum are applied in many industrial processes, such as: mixing, granulation, grinding and sieving. The working principle of devices mentioned above is to put a drum into rotating motion, which causes the movement of the filling. When the filling reaches the so-called angle of repose is reached particles will start off with the process of rolling down. The drum is often set horizontally or at an minor angle, so that it facilitates the transfer of the filling in the direction of its vent (Fig. 2). [1, 2]

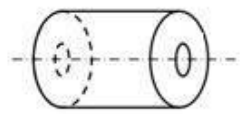

A

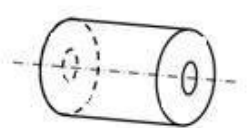

B
Figure 1. Rotating drum set: A - horizontally, B - at an angle, acc. to [1].

While operating of drum mixers five conditions, that occur at different speeds can be observed (Fig. 2). At low rotational speed the filling circulates only and the inner part of it doesn't move - a stationary core - the so-called "kidney" (Fig. 2b). The increase of rotational speed is followed by relaxation of the filling and the free motion of particles on its surface - cataracting is succeeding. This mode of motion is corresponding to many processes related to drum mixers - e.g. the proper mixing (fig. 2c). At the moment, when the gravity is counterbalanced by centrifugal forces the critical rotational speed occur - particles begin to swirl around the perimeter of the drum (fig. 2d). The last type of motion described in the literature, occurs in case when the entire filling swirls around the perimeter of the drum is centrifuging (fig. 2e). [1-5]

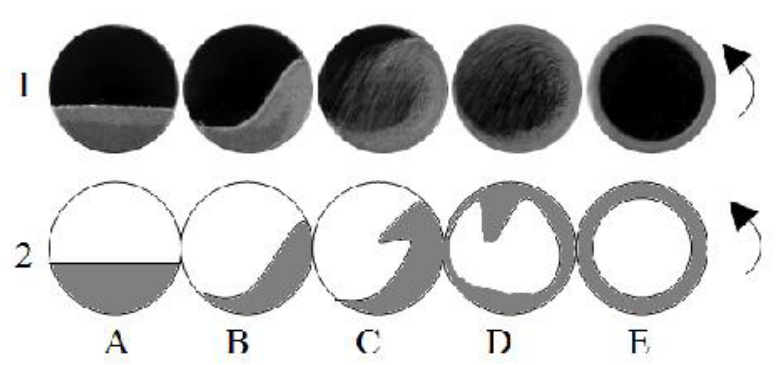

Figure 2. Processes taking place in the drum during operation; 1 - real view, 2 - schematic view; A - zero state, B - cascading motion, $\mathrm{C}$ - cataracting motion, D - critical rotational speed, E - centrifuging motion, acc. to $[2,3,5]$.

\section{Experiment}

\subsection{Test stand}

The research was conducted on a test stand (fig. 3) that includes a drum defined with a diameter of $500 \mathrm{~mm}$ and thickness of $30 \mathrm{~mm}$, embedded on the shaft. The device is setted up into rotating motion by an induction engine. Rotational speed is adjusted by using of an inverter and specified by an optical tachometer.

In order to image registration a camera Canon EOS $600 \mathrm{D}$ with a fast shutter speed-1/1400 s was used. Also the CMOS camera characterized by the pass between frames equals to $2.16 \mathrm{~ms}$ and $\mathrm{PC}$ with the appropriate software were essential for recording of images.

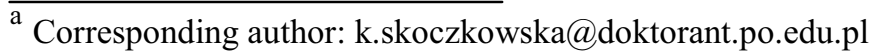


For optimization for visibility of occurring in the filling processes the rear part of the drum was coated with black enamel and three reflectors were used.

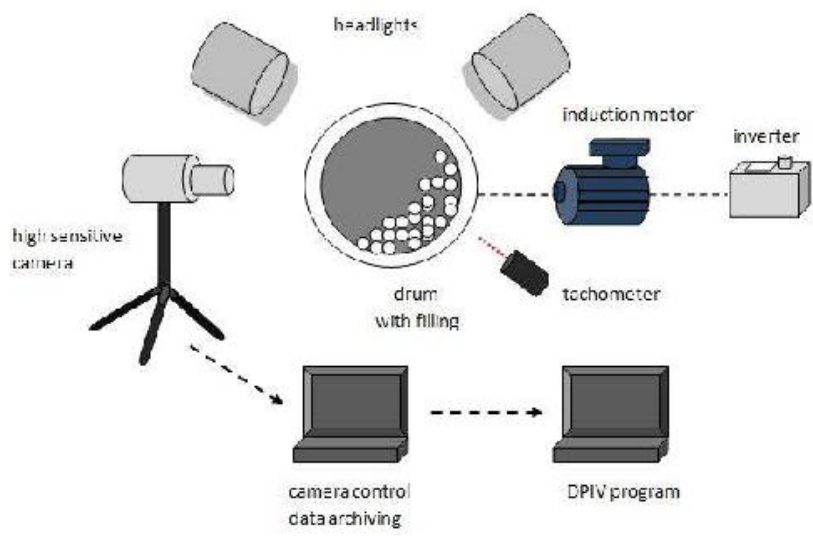

Figure 3. The test stand.

To define the condition of filling behaviour while drum mixer's operating a computer program - DPIV (Digital Particle Image Velocimetry) - was applied. That software allows to designate of local speed fields and of trajectory of the particle movement, therefore the specification of the of the filling behaviour was possible. The principle of operation of PIV programs rely on determining of changes in the pixels position between sequential images (fig. 4). [6, 7]

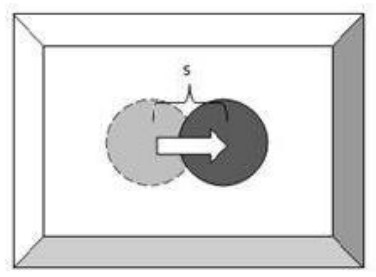

Figure 4. Changing in the position of the particle, acc. to [7].

On the basis of the noted record time of sequential frames velocity vector is determined according to equation:

$$
\vec{v}=\frac{\vec{s}}{p \Delta t}[\mathrm{~mm} / \mathrm{s}]
$$

where: s - the distance traveled [pix], p- graduation [pix $/ \mathrm{mm}], \mathrm{t}$ - delay time between frames [s].

When specifying the velocity vectors for a greater number of particles (as in the case of the filling of the drum mixer) their identification is needed. PIV program perform this based on the appropriate correlation of shades of gray and changes observed in their position at two succeeding images (Fig. 5). [6, 7]

On the basis of particle velocity vectors it is possible to determine phases of particles specific behaviour while operating of drum mixer (Fig. 6).

The study involved three sorts of materials with an average diameter of each of them is amounted to $6 \mathrm{~mm}$ and powder density respectively:
- 1 - artificial material $-1000 \mathrm{~kg} / \mathrm{m}^{3}$,

- 2 - artificial material $-1500 \mathrm{~kg} / \mathrm{m}^{3}$,

- 3 - grain of pea $-800 \mathrm{~kg} / \mathrm{m}^{3}$.

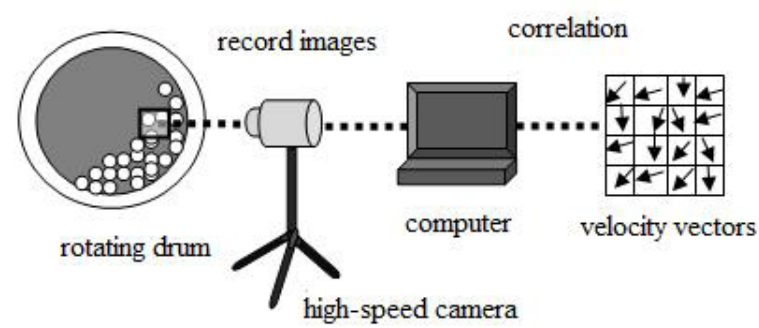

Figure 5. Diagram of determining of particle velocity vectors by PIV-program.

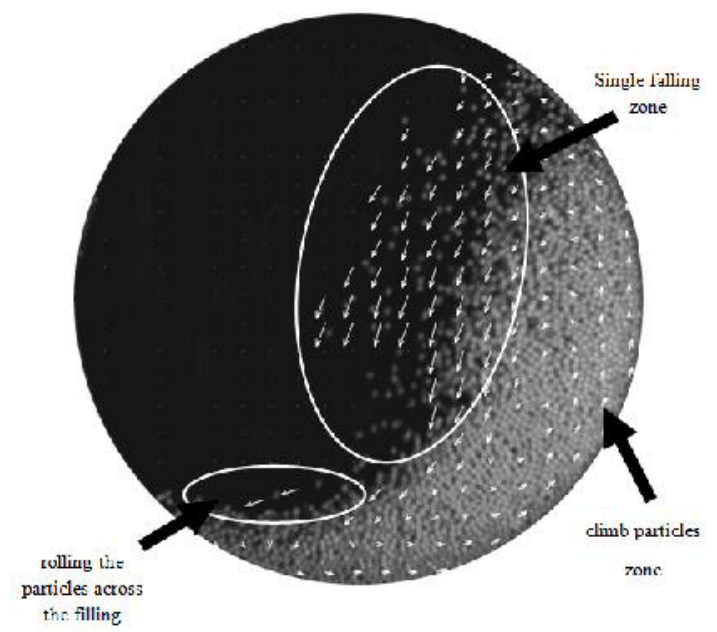

Figure 6. Behaviour of particles while operating of the drum.

Materials coefficients of friction was calculated according to equation (2) and

$$
f=\operatorname{tg} \beta
$$

where: $\beta$ - angle of repose $\left[^{\circ}\right]$.

Table 1. Configuration of angle of repose and the coefficient of friction for analyzed materials.

\begin{tabular}{|c|c|c|}
\hline Material & Angle of repose & $\begin{array}{c}\text { Coefficient } \\
\text { of friction }\end{array}$ \\
\hline 1 & $29^{\circ}$ & 0,55 \\
\hline 2 & $31^{\circ}$ & 0,60 \\
\hline 3 & $36^{\circ}$ & 0,73 \\
\hline
\end{tabular}

\subsection{Methodology}

The research was conducted for five various degrees of the drum filling - from 15 to $35 \%$, by the rotational speed defined from 0 to $100 \mathrm{rpm}$. The aim was to determine the value of the speed at which cataracting occurs. For that aim the PIV method was applied, so that the trajectory of particle motion and thus the behaviour of the filling at different rotational speeds were defined. 
Start of cataracting motion was described for that rotational speed in which the relaxation of deposit occurs, particles after separation from filling exercise free movement inside the apparatus, and then fall on the filling and roll the surface down (Fig. 7).

The end of the cataracting motion was appointed for a so-called state of equilibrium, when particles begin to fall outside of the filling, and thus the process of rolling down is omitted (Fig. 8).

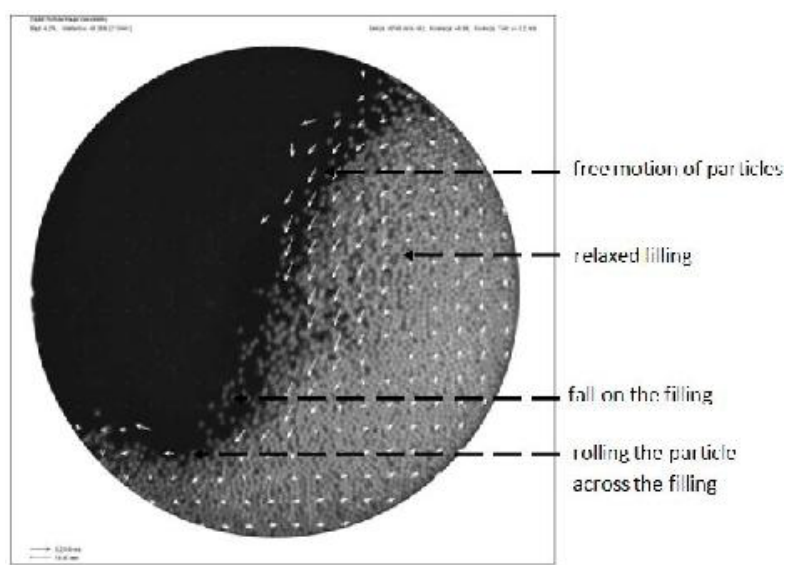

Figure 7. Start of cataracting motion.

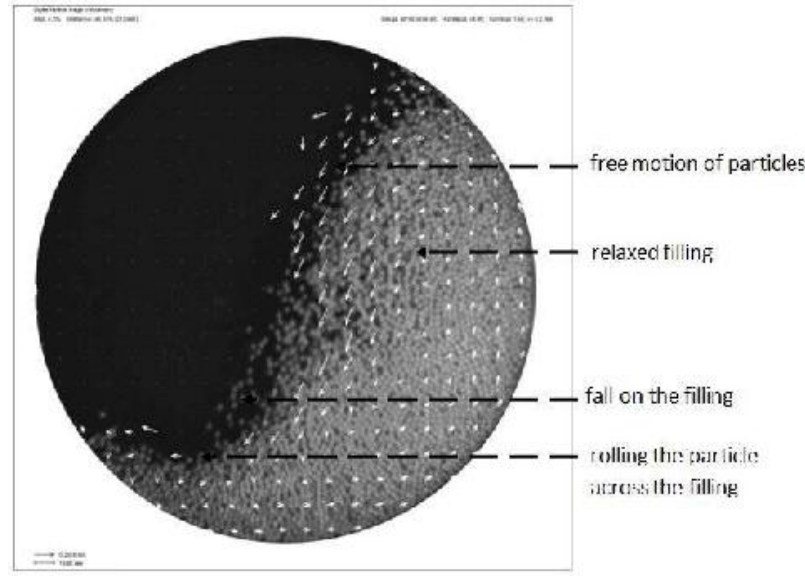

Figure 8. State of equilibrium.

Oyama appointed by an experimental manner a model defining rotational speeds, during which cataracting begins and ends:

$$
n=\frac{C}{D^{0,47} \cdot \varphi^{0,14}}[r p m]
$$

where: $\mathrm{C}$ - constant for: cataracting start $\mathrm{C}=54$, final cataracting $\mathrm{C}=72, \mathrm{D}$ - diameter of the drum $[\mathrm{m}], \varphi$ the fill-in-degree of the drum [\%].

\section{Results and discussion}

Results obtained by experiment have been compared with scores calculated according to equation (3). They are arranged in table 2 and performed using graphs (fig. 9 and 10).

On the beginning of cataracting movement the biggest difference is designated by $5,7 \mathrm{rpm}$ while $25 \%$ fill-in- degree of the drum. That expressed less than a $10 \%$ aberration. In the end-phase of cataracting the biggest discrepancy takes $16.3 \mathrm{rpm}$ for $15 \%$ fill-in-degree of the drum- and is amounted to $27 \%$ aberration.

Table 2. Summary of experimental and calculated results, acc. to Eq. (3).

\begin{tabular}{|c|c|c|c|c|c|c|}
\hline $\begin{array}{c}\text { Characteristics } \\
\text { rotational } \\
\text { speed }\end{array}$ & Material & \multicolumn{5}{|c|}{ Filling ratio } \\
\cline { 3 - 7 } & $\mathbf{1 5 \%}$ & $\mathbf{2 0 \%}$ & $\mathbf{2 5 \%}$ & $\mathbf{3 0 \%}$ & $\mathbf{3 5 \%}$ \\
\hline \multirow{4}{*}{$\begin{array}{c}\text { Cataracting } \\
\text { start }\end{array}$} & Eq. (3) & 51,2 & 49,2 & 47,7 & 46,5 & 45,5 \\
\cline { 2 - 7 } & 2 & 50 & 46 & 44 & 44 & 42 \\
\cline { 2 - 7 } & 3 & 50 & 46 & 42 & 42 & 42 \\
\hline \multirow{4}{*}{$\begin{array}{c}\text { Finally } \\
\text { cataracting }\end{array}$} & Eq. (3) & 68,3 & 65,5 & 63,6 & 62,0 & 60,6 \\
\cline { 2 - 7 } & 1 & 60 & 54 & 52 & 50 & 50 \\
\cline { 2 - 7 } & 2 & 60 & 52 & 50 & 50 & 50 \\
\cline { 2 - 7 } & 3 & 52 & 52 & 48 & 48 & 48 \\
\hline
\end{tabular}

Cataracting start

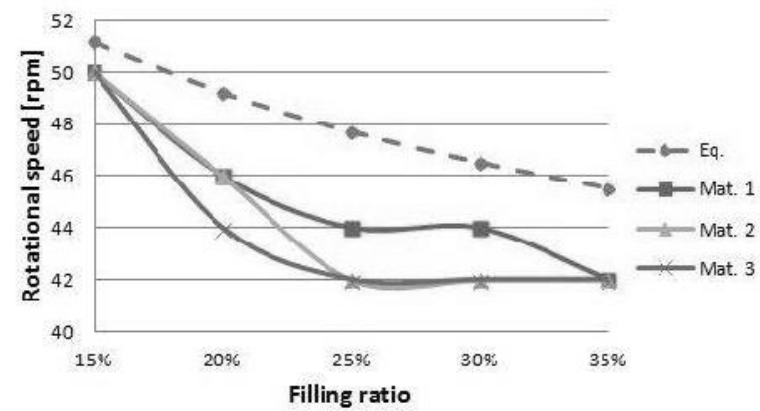

Figure 9. Performance of computed results for cataracting start.

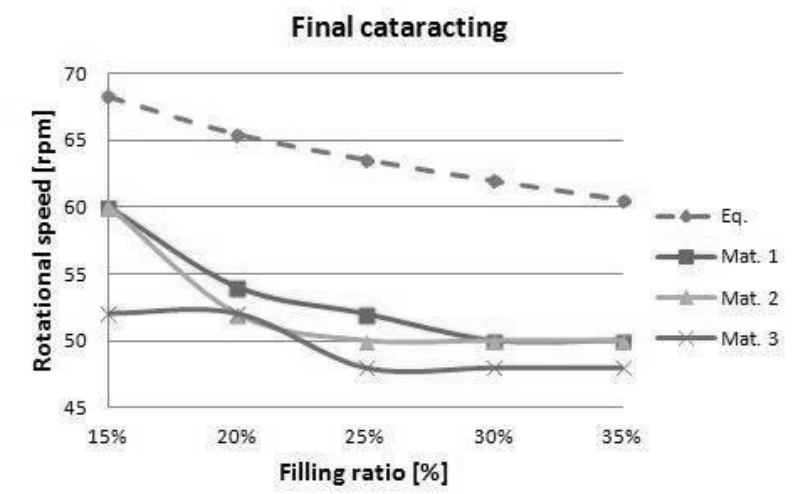

Figure 10. Performance of tested results for final cataracting.

For materials with a higher friction coefficient, the beginning and the end of cataracting motion have taken place for lower rotational speeds. The Equation below gives an attempt to modify equation (3) using the least-squares method, taking into account coefficients of friction derived for tested materials:

$$
n=\frac{C}{D^{0,47} \varphi^{0,14} f^{x}}[r p m]
$$

where: $\mathrm{C}$ - constant for: cataracting start $\mathrm{C}=48$, final cataracting $\mathrm{C}=51.7, \mathrm{D}$ - diameter of the drum $[\mathrm{m}], \varphi$ - 
the fill-in-degree of the drum $\quad[\%], \quad \mathrm{f}$ - coefficient of friction, $\mathrm{x}$ - constant for: cataracting start $\mathrm{x}=0.08$, final cataracting $\mathrm{x}=0.24$.

Table 3 summarizes computed results obtained in the way of according to equation (4).

Table 3. Summary of calculated results, acc. to Eq. (4).

\begin{tabular}{|c|c|c|c|c|c|c|}
\hline \multirow{2}{*}{$\begin{array}{c}\text { Characteristic } \\
\text { rotational } \\
\text { speed }\end{array}$} & Material & \multicolumn{5}{|c|}{ Filling ratio } \\
\cline { 2 - 7 } & $\mathbf{1 5 \%}$ & $\mathbf{2 0 \%}$ & $\mathbf{2 5 \%}$ & $\mathbf{3 0 \%}$ & $\mathbf{3 5 \%}$ \\
\hline \multirow{2}{*}{$\begin{array}{c}\text { Cataracting } \\
\text { start }\end{array}$} & 2 & 47.7 & 45.9 & 44.4 & 43.3 & 42.4 \\
\cline { 2 - 7 } & 3 & 46.7 & 44.8 & 43.4 & 42.4 & 41.4 \\
\hline \multirow{2}{*}{$\begin{array}{c}\text { Final } \\
\text { cataracting }\end{array}$} & 1 & 56.6 & 54.3 & 52.7 & 51.3 & 50.2 \\
\cline { 2 - 7 } & 2 & 55.4 & 53.2 & 51.6 & 50.3 & 49.2 \\
\hline
\end{tabular}

The biggest distinction in experimental and calculated results by the equation (4) tooks $4.6 \mathrm{rpm}$ - which represents less than $8 \%$, by $15 \%$ fill-in-degree of the drum for material number 2 .

Table 4 presents the average arithmetic exception for experimental and computed results obtained with equation (3) and (4). The biggest difference was calculated by equation (3) and (4), for 15\% fill-in-degree of the drum. The average arithmetical deviation for equation (4) amounted to $2.2 \%$, while in case of equation (3) - 20.5\%. Taking into consideration the average arithmetic deviation, equation (4) describes cataracting motion in a more accurate way than equation (3).

Table 4. The arithmetic mean deviation for the results computed by Eq. (3) and (4).

\begin{tabular}{|c|c|c|c|}
\hline $\begin{array}{c}\text { Characteristic } \\
\text { rotational speed }\end{array}$ & Eq. & $\begin{array}{c}\text { Arithmetic mean } \\
{[\mathbf{r p m}]}\end{array}$ & $\begin{array}{c}\text { Arithmetic mean } \\
{[\%]}\end{array}$ \\
\hline Cataracting start & $(3)$ & 3.5 & 5.8 \\
\cline { 2 - 4 } & $(4)$ & 1.1 & 1.8 \\
\hline Final cataracting & $(3)$ & 12.3 & 20.5 \\
\cline { 2 - 4 } & $(4)$ & 1.3 & 2.2 \\
\hline
\end{tabular}

Table 5. shows the coefficient of Pearson's correlation for equation (3) and (4).

Table 5. The coefficient of Pearson's correlation for Eq. (3) and (4).

\begin{tabular}{|c|c|c|}
\hline $\begin{array}{c}\text { Characteristic } \\
\text { rotational speed }\end{array}$ & Eq. & $\begin{array}{c}\text { Coefficient of } \\
\text { Pearson's correlation }\end{array}$ \\
\hline Cataracting start & $(3)$ & 0.92 \\
\cline { 2 - 3 } & $(4)$ & 0.93 \\
\hline \multirow{2}{*}{ Final cataracting } & $(3)$ & 0.80 \\
\cline { 2 - 3 } & $(4)$ & 0.90 \\
\hline
\end{tabular}

The biggest improvement in the correlation occurred for maximum rotational speed - increased from 0.8 to 0.9. It should be emphasized that equation (4) is a derivative of equation (3), and it takes into consideration only the three tested materials. Therefore, it is essential to perform subsequent research and to analyse the correctness of the proposed equation (4).

\section{Conclusions}

With an increase in the fill-in-degree of the drum rotational speeds describing the process of cataracting motion decreases.

Surface quality of the materials used as filling affects its behavior while drum mixer's operating. The higher the coefficient of friction, the lower the value of characteristic rotational speed occurs.

Equation (3) does not take to factor in the basic parameter of granular material, which is the coefficient of friction. In this paper an attempt to revision of its notation have been undertaken, so that a better description of cataracting motion will be achieved equation (4). The average aberration for the proposed formula is amounted to $2.2 \%$, while for equation (3) $20.5 \%$.

The proposed model does not take into account the coefficient of friction between the inner exterior of the drum and the filling, so it obliges to further study on processes occurring in drum mixers.

\section{References}

1. Boss J., Mieszalniki z komora obrotowa, Mieszanie materiałów ziarnistych, PWN, Warszawa/Wrocław, chap. 9.2, 134-143 (1987)

2. Soheili A. and e.a., Experimental study of the repose angle of corn seeds in rotating drums, World Applied Sciences Journal, vol. 13, 1996-2004 (2011)

3. Chou S.H., Hsiau S.S., Dynamic properties of immersed granular matter in different flow regimes in a rotating drum, Powder Technology, vol. 226, 99-106 (2012)

4. Wodziński P., Drum screens in mineral minning, Górnictwo i Geoinżynieria, vol. 3, 347-354 (2006)

5. Raiko S., Geometrical characteristics of the solid bed in a rotary kiln, Journal of Chemical Technology and Metallurgy, vol. 49, 82-89 (2014)

6. Zając D., Ulbrich R., Nieinwazyjne metody badań przepływów dwufazowych gaz-ciecz, Opole, 41-49 (2005)

7. Suchecki W., Albrudziński S., Kowalewski T., Metoda analizy pola prędkości z uwzględnieniem istnienie dużych obiektów $w$ przepływie, Inżynieria i Aparatura Chemiczna, vol. 5, 6-13 (2003)

KAPITAL LUDZKI
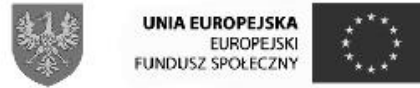

"PhD Scholarships - investment in faculty of the Opolskie Voivodeship" Project co-financed by the European Union under The European Social Fund 